\title{
Octreotide's Role in the Management of Sulfonylurea-Induced Hypoglycemia
}

\author{
Patrick P. Dougherty • Wendy Klein-Schwartz
}

Published online: 30 March 2010

(C) American College of Medical Toxicology 2010

\begin{abstract}
The objective is to evaluate the evidence regarding octreotide's efficacy as a treatment for sulfonylurea-induced hypoglycemia. A search of PubMed for articles published from 1965 to 2008 using combinations of the terms octreotide, antidote, sulfonylurea, overdose, poisoning, and toxicity was performed. References from identified articles were reviewed for additional sources. Animal studies, case reports, case series, and randomized controlled trials were evaluated. An animal model of sulfonylurea overdose demonstrates that octreotide reduces the number of refractory sulfonylurea-induced hypoglycemic episodes. Published case reports describe the use of octreotide to prevent recurrent hypoglycemia after sulfonylurea overdose. A retrospective case series demonstrates that administration of octreotide decreases the need for supplemental dextrose boluses as well as hypoglycemic events. Two prospective, controlled trials determined that octreotide and supplemental dextrose increase blood glucose concentrations with fewer hypoglycemic events. Based on animal and human data, there is sufficient evidence to recommend the use of octreotide with supplemental dextrose for the treatment of sulfonylurea-induced hypoglycemia.
\end{abstract}

Keywords Octreotide $\cdot$ Sulfonylurea $\cdot$ Overdose .

Poisoning $\cdot$ Antidote

P. P. Dougherty $\cdot$ W. Klein-Schwartz

Maryland Poison Center,

University of Maryland School of Pharmacy,

Baltimore, MD 21201, USA

P. P. Dougherty $(\square)$

Maryland Poison Center,

220 Arch Street, Room 01-110,

Baltimore, MD 21201, USA

e-mail: pdougher@rx.umaryland.edu

\section{Introduction}

Sulfonylurea overdose results in hypoglycemia. In some cases, management of sulfonylurea overdose with intravenous dextrose leads to hyperglycemia which promotes insulin release from the pancreas and recurrent hypoglycemia. Evidence of octreotide's efficacy as a treatment for sulfonylurea-induced hypoglycemia was sought. One author (PD) performed a search of PubMed for sources dated from 1965 to 2008 using combinations of the terms octreotide, antidote, sulfonylurea, overdose, poisoning, and toxicity. References from identified articles were reviewed for additional sources. Identified articles, including animal studies, case reports, case series, and randomized controlled trials were evaluated. This article describes the toxicity and mechanism of sulfonylureas as well as evidence regarding the use of octreotide for sulfonylurea-induced hypoglycemia.

\section{Background}

The incidence of type 2 diabetes mellitus in the USA is growing [1]. The most often prescribed drug class for management of patients with type 2 diabetes is the sulfonylureas. In 2007, there were 4,384 sulfonylurea exposures reported to the American Association of Poison Control Centers National Poison Data System, accounting for $34 \%$ of overdoses from oral hypoglycemics and antihyperglycemic drugs [2]. For single-substance exposures to oral sulfonylureas, $84 \%$ were unintentional (e.g., accidental or therapeutic error) and $50 \%$ involved children under 6 years of age. Reflecting their high potential for toxicity, $72 \%$ of single-substance oral sulfonylurea exposures were managed in a healthcare facility. 


\section{Sulfonylurea Toxicity}

Sulfonylurea overdose is associated with hypoglycemia. Onset of hypoglycemia may be delayed up to $12 \mathrm{~h}$, and duration may be prolonged for days after overdoses. Patients who are hypoglycemic experience dizziness, weakness, headache, confusion, lethargy, slurred speech, coma, and seizures. Other clinical effects include tachycardia, palpitations, nausea, and diaphoresis. Protracted hypoglycemia can result in death.

Sulfonylureas have a narrow therapeutic index. Case reports and several studies on sulfonylurea overdose in children have found that hypoglycemia occurs with single tablet ingestions [3, 4]. Hypoglycemia usually occurs within $8 \mathrm{~h}$ but may be delayed in patients treated with prophylactic intravenous glucose [4-6]. In adults, hypoglycemia with therapeutic use may be due to wrong dose, double dosing, drug interactions, impaired drug metabolism, or decreased drug excretion. Potential for hypoglycemia associated with dosage increases is well described, especially in older patients, sometimes with fatal outcomes [7, 8]. Review of national poison center data found 14 sulfonylurea-associated fatalities reported between 1992 and 1996 in adults aged 18 to 79 years [9]. Eleven cases were the result of suicides and involved co-ingestants.

\section{Sulfonylurea-Induced Recurrent Hypoglycemia}

A potential complication of treatment of sulfonylurea-induced hypoglycemia with intravenous dextrose is recurrent hypoglycemia. Dextrose administration results in hyperglycemia which in turn potentiates insulin release from the pancreas leading to recurrent hypoglycemia. Re-administration of dextrose perpetuates this cycle, resulting in high dextrose requirements and the need for frequent monitoring of blood glucose levels.

\section{Mechanisms of Action of Sulfonylureas}

Pancreatic $\beta$ cells release insulin in response to elevated blood glucose. The pancreatic $\beta$ cells metabolize glucose which generates ATP and increases the ATP/ADP ratio. This in turn leads to closing of a membrane ATP-sensitive potassium channel which results in membrane depolarization, calcium influx, and insulin secretion [10] (Fig. 1). Patients with type 2 diabetes have some degree of pancreatic insulinreleasing function but exhibit impaired insulin secretion and peripheral insulin resistance. Sulfonylureas potentiate insulin release in these patients as well as in normal subjects. Sulfonylureas bind to the sulfonylurea receptor type 1 (SUR1) on pancreatic $\beta$-cell membrane, which is associated with ATP-dependent potassium channels. Potassium channel activity is inhibited preventing potassium efflux which leads to membrane depolarization, opening of voltage-gated calcium channels with influx of calcium which subsequently results in insulin release [11, 12]. Sulfonylureas differ in their binding affinity to SUR1; the greater the affinity, the greater the potency of the drug.

\section{Clinical Management: Prevention and Initial Management of Hypoglycemia}

Ideally, the primary goal of treatment of sulfonylurea overdose is prevention of hypoglycemia. A secondary goal is the return of euglycemia in patients who develop hypoglycemia. Patients with recent acute sulfonylurea overdoses should receive activated charcoal if mental status is deemed adequate [13]. Carbohydrate-containing food can be provided to patients if they are awake and alert enough to eat and protect their airway. Blood glucose concentrations should be measured once every hour for asymptomatic patients or more frequently for those with signs or symptoms of hypoglycemia.

The management of sulfonylurea-induced hypoglycemia initially includes the administration of rapidly metabolized carbohydrates, such as intravenous dextrose or oral glucose tablets and gels, followed by a continuous intravenous infusion in order to try to prevent recurrent hypoglycemia [14]. Bolus doses of dextrose are usually $0.5-1.0 \mathrm{~g} / \mathrm{kg}$ given intravenously. Adults are typically provided a $50-\mathrm{mL}$ bolus of $50 \%$ dextrose $(25 \mathrm{~g})$ while children and infants are given $2 \mathrm{~mL} / \mathrm{kg}$ boluses of $25 \%$ and $5 \mathrm{~mL} / \mathrm{kg}$ of $10 \%$ dextrose, respectively. Repeated boluses and titration of the continuous intravenous dextrose infusion may be required for sulfonylurea-induced refractory hypoglycemia. Patients with renal insufficiency or heart failure may have difficulty with fluid overload from the continuous intravenous infusion of dextrose-containing free water [15]. If this initial therapy with intravenous dextrose does not adequately address the hyperinsulinemic state produced by the sulfonylurea, then other treatments should be considered.

\section{Glucagon and Diazoxide}

Therapy with glucagon or diazoxide was used historically. Glucagon binds to hepatic glucagon receptors and promotes glycogenolysis and gluconeogenesis. However, glucagon also promotes insulin secretion by the pancreas, which can further worsen the hyperinsulinemic state caused by sulfonylureas, by causing an increase in blood glucose concentrations as well as by binding to pancreatic receptors [16] (Fig. 1). Diazoxide opens pancreatic potassium 


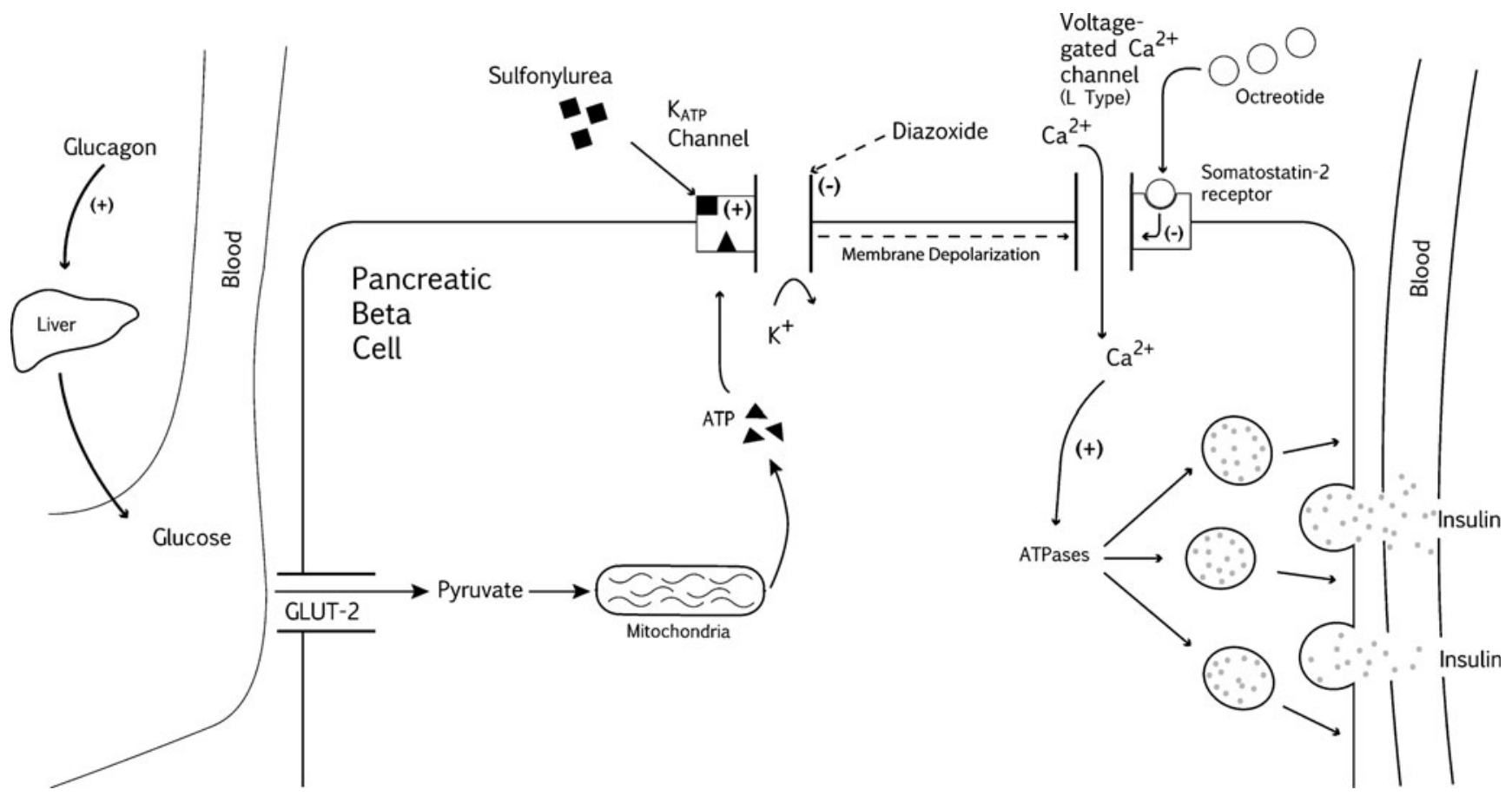

Fig. 1 Mechanism of sulfonylureas antidotes

channels, causing a hyperpolarized state which prevents the opening of voltage-gated calcium channels, thereby blocking the influx of calcium and subsequent secretion of insulin [17] (Fig. 1). Risks associated with diazoxide include hypotension, tachycardia, and sodium and fluid retention. According to the Food and Drug Administration (FDA) website, intravenous diazoxide is no longer being manufactured [18]. Therapy with glucagon and diazoxide has fallen out of favor with increased use of octreotide.

\section{Octreotide}

The long-acting, synthetic somatostatin analog, octreotide, is FDA-approved for the treatment of acromegaly, metastatic carcinoid symptoms, and vasoactive intestinal secreting tumors [19]. It has also been used for the cessation of upper gastrointestinal bleeding [20] and to correct refractory hypoglycemia caused by sulfonylurea overdoses [21-27]. Octreotide can be administered either intravenously or subcutaneously, with both routes having equivalent bioavailability $[28,29]$ (Table 1). A once-monthly injectable depot formulation of octreotide is available (Sandostatin LAR ${ }^{\circledR}$; Novartis Pharma, Basel, Switzerland) but is not indicated for use as an antidote for sulfonylurea-induced refractory hypoglycemia. The depot formulation releases octreotide slowly via microsphere degradation, precluding its use in acute sulfonylurea overdose. Its duration of action would also be expected to substantially outlast the length of therapy required.
Octreotide is well-tolerated [30]. Adverse effects associated with the administration of octreotide are usually mild (Table 1). Bradycardia and prolongation of the QTc interval have been reported, but coincide with long-term, chronic use of octreotide in acromegalics [19]. Accidental overdoses of 2,400 to $6,000 \mu \mathrm{g} /$ day have occurred, causing mild similar symptoms as described above, indicating that octreotide has a wide therapeutic window. Adverse effects of octreotide in

Table 1 Specifics of octreotide for sulfonylurea-induced hypoglyemia

\begin{tabular}{ll}
\hline Characteristic & Specific parameter value \\
\hline Mechanism of action & $\begin{array}{c}\text { Binds to somatostatin-2 receptors } \\
\text { located on pancreatic } \beta \text { cells, } \\
\text { preventing the influx of calcium } \\
\text { required for insulin secretion }\end{array}$ \\
& $30 \mathrm{~min}$ \\
Peak effect & $1.5 \mathrm{~h}$ \\
Half-life & $50,100,200,500,1,000 \mu \mathrm{g} / \mathrm{mL}$ \\
Injection solution concentrations & $\mathrm{SC}-\mathrm{preferred}$ \\
Routes & $\mathrm{IV}$ \\
& $50-100 \mu \mathrm{g}$ every $6-12 \mathrm{~h}$ \\
Dosing Schedule-Adults & $1-2 \mu \mathrm{g} / \mathrm{kg}$ up to $50 \mu \mathrm{g}$ every \\
Dosing Schedule-Children & $6-12 \mathrm{~h}$ \\
& $4-6 \mathrm{~h}$ (IV) \\
Duration of action & $6-12 \mathrm{~h}(\mathrm{SC})$ \\
& Hyperglycemia, injection site \\
Adverse Effects & pain, nausea, abdominal pain, \\
& flatulence, diarrhea \\
\hline
\end{tabular}

$I V$ intravenous; $S C$ subcutaneous 
pediatric patients have been reported to the FDA [31]. Most of these cases involved children aged less than 6 months old who were administered octreotide for indications not approved by the FDA and for longer periods of time than required for treatment of sulfonylurea overdose. None of these children were administered octreotide for correction of sulfonylurea-induced hypoglycemia. Adverse effects reported included hypotension, bradycardia, hyper- and hypoglycemia, hypoadrenalism, metabolic acidosis, fluid retention, necrotizing entercolitis, and osteonecrosis. The potential benefit of administering a few doses of octreotide to a child with life-threatening sulfonylurea-induced hypoglycemia likely outweighs the risk of developing the adverse effects documented with longer durations of therapy. However, with only three published case reports of octreotide administration for sulfonylurea overdose in children under 6 years of age, close monitoring for adverse effects is advised $[23,26]$.

\section{Mechanism of Action of Octreotide}

Patients who developed hypoglycemia with therapeutic doses of sulfonylureas have been given supplemental dextrose and octreotide, with subsequent correction of the hypoglycemia $[15,32]$. Octreotide prevents rebound hypoglycemia after treatment of sulfonylurea overdose with dextrose. By mimicking somatostatin, octreotide suppresses the secretion of gastrin, cholecystokinin, growth hormone, glucagon, and insulin [19]. Voltage-gated calcium channels on pancreatic beta cells are bound by G-protein-coupled somatostatin-2 receptors. When octreotide binds to the somatostatin receptors, the calcium channels close, preventing the influx of calcium and subsequent secretion of insulin (Fig. 1). This mechanism lends to the effectiveness of octreotide for treatment of sulfonylurea-induced hypoglycemia, as it binds "downstream" from where sulfonylureas exert their effects on the $\beta$ cells and prevents an event necessary for the secretion of insulin.

Animal studies, case reports, case series, and clinical trials were reviewed for evidence of octreotide's efficacy in treating sulfonylurea-induced hypoglycemia.

\section{Animal Study}

Gul et al. investigated the effectiveness of three doses $(25,50,100 \mu \mathrm{g})$ of octreotide in a rabbits following oral administration of gliclazide $100 \mathrm{mg}$ [33]. There was a significant difference in supplemental dextrose doses and number of hypoglycemic events that occurred between the rabbits provided only intravenous dextrose and octreotide 25 and $100 \mu \mathrm{g}$. The authors concluded that a single dose of octreotide $100 \mu \mathrm{g}$ reduces the number of refractory sulfonylurea-induced hypoglycemic episodes.

\section{Case Reports and Case Series}

There are numerous case reports describing treatment of sulfonylurea overdoses with octreotide. In 2002, Carr and Zed described glyburide overdoses in two patients with refractory hypoglycemia despite dextrose $50 \%$ boluses and $10 \%$ infusions who demonstrated fewer hypoglycemic episodes and lower dextrose requirements with octreotide $50 \mu \mathrm{g}$ every $8 \mathrm{~h}$ for three doses [24]. These authors provide a summary of six previously reported cases that demonstrate the benefits of octreotide therapy. Subsequent to Carr and Zed's report, there have been 13 case reports on the treatment of sulfonylurea-induced hypoglycemia with octreotide, including two cases in young children $[15,22$, 24-26, 32]. These 13 cases are summarized in Table 2. Excluding the 22 patients who received $75 \mu \mathrm{g}$ of octreotide reported by Fasano et al. (see discussion below), there were 11 patients with chronic sulfonylurea toxicity who received subcutaneous octreotide $[15,23,25,27,32,34]$. Nine of these patients received from one to four $50 \mu \mathrm{g}$ doses, and two patients received a single $100 \mu \mathrm{g}$ dose. Of 11 patients with acute overdoses who received subcutaneous octreotide, patients received from one to four doses of $40 \mu \mathrm{g}(N=1)$, $50 \mu \mathrm{g}(N=7)$, and $100 \mu \mathrm{g}(\mathrm{N}=2)$; one additional patient was switched to $100 \mu \mathrm{g}$ doses after an initial $50-\mu \mathrm{g}$ dose $[15,23,27]$. Patients with acute overdoses who presented earlier received more octreotide. In the patients for whom this information was available, the four patients treated at $8 \mathrm{~h}$ or earlier after the overdose received three to four octreotide doses compared to one to two doses in the four patients treated after $8 \mathrm{~h}$. Patients experienced an average of 3.3 pre-octreotide hypoglycemic episodes compared with 0.4 episodes post-octreotide. Comparing patients with chronic and acute overdoses, $36.4 \%$ and $30 \%$ of patients experienced hypoglycemic episodes post-octreotide, respectively. Including the 22 patients reported by Fasano et al., $42.4 \%$ of chronic toxicity patients experienced post-octreotide hypoglycemia [34]. All were single episodes except one acute and one chronic patient who each experienced two post-octreotide hypoglycemic episodes.

\section{Retrospective Studies}

McLaughlin et al. performed a retrospective chart review of nine patients who ingested either glyburide or glipizide in order to evaluate the effect of octreotide on glucose requirements and number of hypoglycemic episodes [27]. From one to four subcutaneous doses of octreotide doses 


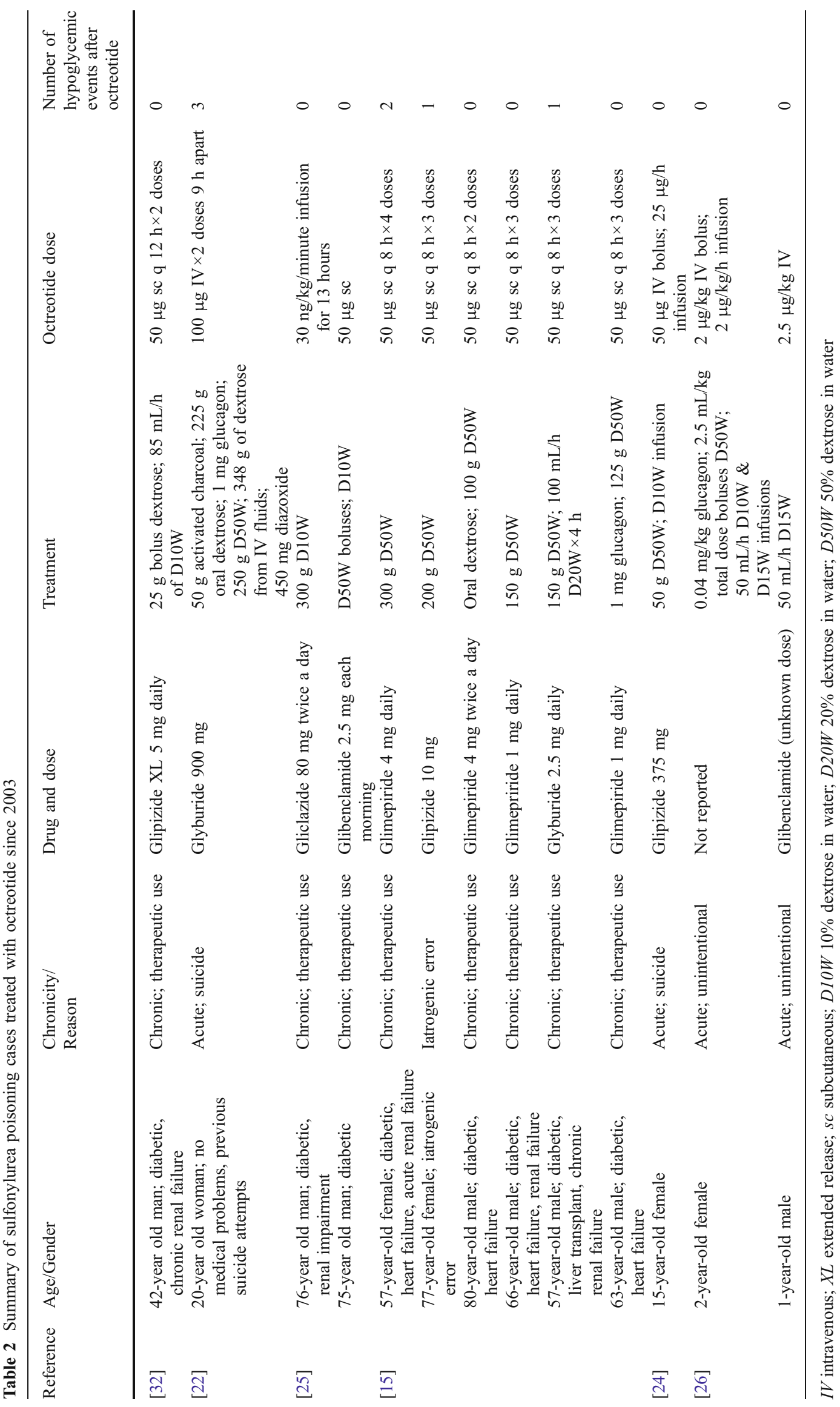


$40-100 \mu \mathrm{g}$ were administered. There were significantly more hypoglycemic events before octreotide (mean 3.2) as compared to after the administration of octreotide (mean $0.2, p=0.008$ ). The number of dextrose boluses required to correct hypoglycemia was significantly decreased after octreotide (mean of 2.9 compared to 0.2 ampules, $p=$ 0.004). The risk of developing sulfonylurea-induced refractory hypoglycemia was 27 times higher before treatment with octreotide as compared to after octreotide $(p<0.001)$. The majority of the patients were administered octreotide $8 \mathrm{~h}$ or more after the time of ingestion. As time progresses after sulfonylurea poisoning and the drugs are metabolized and eliminated, the risks of developing hypoglycemia decrease. This fact confounds the idea that octreotide was solely responsible for decreasing the number of hypoglycemic events. Other limitations include a retrospective design and small number of cases.

\section{Prospective Studies}

Fasano et al. conducted a prospective, randomized, doubleblind, placebo-controlled trial to test the hypothesis that the addition of octreotide to standard intravenous dextrose therapy would increase blood glucose concentrations in patients with sulfonylurea-induced hypoglycemia [34]. Participants were adults who presented to an emergency department with hypoglycemia and were included in the study if their prescription medications included a sulfonylurea either alone or in combination with another oral antihyperglycemic agent or insulin. After initial correction of hypoglycemia plus intravenous 50\% dextrose bolus along with a standardized oral carbohydrate regimen, patients were randomized to receive either a subcutaneous injection of octreotide $75 \mu \mathrm{g}$ or a saline placebo. For the first $8 \mathrm{~h}$ after randomization, blood glucose concentrations of the patients in the octreotide arm were significantly higher than the concentrations of the patients in the placebo arm $(p<0.0001)$. Ten of 22 patients $(45 \%)$ experienced a single episode of blood glucose concentrations of less than $60 \mathrm{mg} / \mathrm{dL}$ after octreotide. Six of the 18 (33\%) patients in the placebo group experienced hypoglycemia, but the events occurred more frequently (13 episodes). The only significant difference in the blood glucose concentrations between the treatment groups occurred between 4 to $8 \mathrm{~h}$ after the administration of octreotide. The investigators concluded that the addition of octreotide to standard therapy for sulfonylurea-induced hypoglycemia increases blood glucose concentrations for $8 \mathrm{~h}$ and that hypoglycemia occurs less often after the administration of octreotide. Patients being prescribed both a sulfonylurea and insulin were included in the study; octreotide would not correct hypoglycemia from exogenous insulin. Thirty patients received a standard hospital food tray (average 600 calories) rather than the standard oral carbohydrate regimen (360 calories), which may confound the premise that octreotide was the only modality responsible for maintaining euglycemia or hyperglycemia.

Boyle et al. performed a volunteer crossover study to test the hypothesis that octreotide and intravenous dextrose would be superior to conventional therapy of either intravenous dextrose or diazoxide and dextrose for the treatment of sulfonylurea poisoning [30]. To date, this is the only study comparing two different antidotes for the treatment of sulfonylurea-induced hypoglycemia. Eight volunteers received $1.45 \mathrm{mg} / \mathrm{kg}$ of glipizide. Blood glucose concentrations were measured until they were hypoglycemic, at which point a bolus of dextrose was administered, and the subjects were randomized to receive one of three different therapies: standard dextrose therapy $(20 \%$ intravenous dextrose infusion), bolus intravenous doses of diazoxide $300 \mathrm{mg}$ every $4 \mathrm{~h}$ and standard dextrose therapy, or a continuous intravenous infusion of octreotide $30 \mathrm{ng} / \mathrm{kg} / \mathrm{min}$ and standard dextrose therapy. The dextrose infusions were adjusted to maintain euglycemia. Five hours after the ingestion of the sulfonylurea, the subjects were administered a second dextrose bolus to test for suppression of sulfonylurea-induced glucose-stimulated insulin release, and the time to hypoglycemia was calculated. After $8 \mathrm{~h}$, the therapies were discontinued to examine if hypoglycemia would recur; subjects were provided intravenous dextrose if they developed hypoglycemia. Blood glucose concentrations of subjects given octreotide took $6.5 \mathrm{~h}$ to decrease to $85 \mathrm{mg} /$ $\mathrm{dL}$ after a $50 \%$ intravenous dextrose bolus, as compared to $3 \mathrm{~h}$ for the other two study groups $(p<0.001)$. Dextrose requirements did not significantly differ between the dextrose-only and diazoxide groups but were significantly greater than the dextrose requirements of the octreotide arm $(p<0.001)$. Only two patients in the octreotide group developed blood glucose concentrations less than $65 \mathrm{mg} /$ $\mathrm{dL}$ with the hypoglycemia occurring greater than $3 \mathrm{~h}$ after discontinuation of therapy. Blood glucose concentrations fell below $65 \mathrm{mg} / \mathrm{dL}$ within $1.5 \mathrm{~h}$ after stopping therapy in the other two arms for each subject. Plasma insulin concentrations were approximately five times greater with dextrose alone or in combination with diazoxide as compared with octreotide and dextrose $(p<0.01)$. The investigators concluded that "octreotide is a physiologically specific, well tolerated antidote for the hyperinsulinemia induced by a large sulfonylurea overdose and should be strongly considered as a logical therapeutic alternative for this metabolic emergency." A strength of this study is the crossover design. However, only five volunteers completed the full study; three participants did not complete the diazoxide arm. The rates of adverse effects of the different treatments were not compared. 
Neither of the prospective studies included patients with intentional, suicidal overdoses of sulfonylureas. This limits the generalizability of their findings. Suicidal patients usually ingest larger quantities may co-ingest other drugs and develop more severe prolonged clinical effects. Higher doses, and possibly more frequent dosing, of octreotide might be required in this subset of patients.

\section{Summary}

Based on animal and human data, there is sufficient evidence to recommend the use of octreotide with supplemental dextrose for the treatment of sulfonylurea-induced hypoglycemia in patients for whom supplemental dextrose alone is insufficient. Subcutaneous doses of 50-100 $\mu$ g every $8 \mathrm{~h}$ will be effective in most patients with acute overdose or chronic toxicity. The dose and duration of octreotide administration are lower than those required for other indications, so adverse effects are expected to be less frequent when octreotide is used short term for sulfonylurea-induced refractory hypoglycemia. Future studies are needed to assess the extent to which the time post-ingestion of sulfonylurea at which octreotide is initiated impacts on the dose, dosing interval, and number of doses of octreotide required.

Acknowledgements We acknowledge Shannon Tucker's contribution to designing the figure.

Conflict of interest There are no conflicts of interest including, but not limited to, consulting fees, paid expert testimony, employment, grants, honoraria, patents, royalties, stock, or other financial or material gain that may involve the subject matter of this manuscript.

\section{References}

1. Winer N, Sowers JR (2004) Epidemiology of diabetes. J Clin Pharmacol 44(4):397-405. doi:10.1177/0091270004263017

2. Bronstein AC, Spyker DA, Cantilena LR Jr, Green JL, Rumack BH, Heard SE (2008) 2007 Annual report of the American Association of Poison Control Centers' National Poison Data System (NPDS): 25th Annual report. Clin Toxicol 46(10):9271057. doi:10.1080/15563650802559632

3. Szlatenyi CS, Capes DF, Wang RY (1998) Delayed hypoglycemia in a child after ingestion of a single glipizide tablet. Ann Emerg Med 31(6):773-776. doi:10.1016/S0196-0644(98)70240-9

4. Quadrani DA, Spiller HA, Widder P (1996) Five year retrospective evaluation of sulfonylurea ingestion in children. Clin Toxicol 34 (3):267-270

5. Spiller HA, Villalobos D, Krenzelok EP, Anderson BD, Gorman SE, Rose SR, Fenn J, Anderson DL, Muir SC, Rodgers GC (1997) Prospective multicenter study of sulfonylurea ingestion in children. J Pediatr 131:141-146. doi:10.1016/S0022-3476(97) 70138-0

6. Little GL, Boniface KS (2005) Are one or two dangerous? Sulfonylurea exposure in toddlers. J Emerg Med 28(3):305-310. doi:10.1016/j.jemermed.2004.09.012
7. Coates JR, Robbins JJ (1959) Severe hypoglycemic shock due to chlorpropamide. J Am Med Assoc 170(8):941-942

8. McKendry JBR (1957) Fatal hypoglycemic coma from the use of tolbutamide (Orinase). Can Med Assoc J 76:572-573

9. Mullins ME, Warden CR, Horowitz BZ (1999) Delayed hypoglycemia after ingestion of a single glipizide tablet. Ann Emerg Med 33(1):129-130. doi:10.1016/S0196-0644(99)70437-3

10. Polonsky KS, Semenkovich CF (2001) The pancreatic $\beta$ cell heats up: UCP2 and insulin secretion in diabetes. Cell 105(6):705-707. doi:10.1016/S0092-8674(01)00389-0

11. Yan FF, Casey J, Shyng SL (2006) Sulfonylureas correct trafficking defects of disease-causing ATP-sensitive potassium channels by binding to the channel complex. J Biol Chem 281 (44):33403-33413. doi:10.1074/jbc.M605195200

12. Cheng AY, Fantus IG (2005) Oral antihyperglycemic therapy for type 2 diabetes mellitus. CMAJ 172(2):213-226. doi:10.1503/ cmaj. 1031414

13. Kivisto KT, Neuvonen PJ (1990) The effect of cholestyramine and activated charcoal on glipizide absorption. Br J Clin Pharmacol 30:733-736

14. Rowden AK, Fasano CJ (2007) Emergency management of oral hypoglycemic drug toxicity. Emerg Med Clin North Am 25:347356. doi:10.1016/j.emc.2007.02.010

15. Fleseriu M, Skugor M, Chinnappa P, Siraj ES (2006) Successful treatment of sulfonylurea-induced prolonged hypoglycemia with use of octreotide. Endocr Pract 12(6):635-640

16. Thoma ME, Glauser J (1996) Persistent hypoglycemia and hyperinsulinemia: caution in using glucagon. Am J Emerg Med 14:99-101. doi:10.1016/S0735-6757(96)90029-7

17. Altszuler N, Hampshire J, Moraru E (1977) On the mechanism of diazoxide-induced hyperglycemia. Diabetes 26:931-935. doi: $10.2337 /$ diabetes.26.10.931

18. US Food and Drug Administration (2009) Drugs at FDA. Silver Spring: US Food and Drug Administration, Available from: http:// www.accessdata.fda.gov/scripts/cder/drugsatfda/index.cfm

19. Novartis Pharma (2008) Product information: Sandostatin (octreotide acetate). Novartis Pharma, Basel

20. Jenkins SA, Taylor BA, Nott DM, Ellenbogen S, Haggie J, Shields R (1992) Management of massive upper gastrointestinal haemorrhage from multiple sites of peptic ulceration with somatostatin and octreotide - a report of five cases. Gut 33:404407. doi:10.1136/gut.33.3.404

21. Braatvedt GD (1997) Octreotide for the treatment of sulphonylurea induced hypoglycemia in type 2 diabetes. NZ Med J 110:189-190

22. Green RS, Palatnick W (2003) Effectiveness of octreotide in a case of refractory sulfonylurea-induced hypoglycemia. J Emerg Med 25(3):283-287. doi:10.1016/S0736-4679(03)00204-X

23. Carr R, Zed PJ (2002) Octreotide for sulfonylurea-induced hypoglycemia following overdose. Ann Pharmacother 36:17271732. doi:10.1345/aph.1C076

24. Soderstrom J, Murray L, Daly FFS, Little M (2006) Toxicology case of the month: oral hypoglycaemic overdose. Emerg Med J 23:565-567. doi:10.1136/emj.2006.034868

25. Crawford BAL, Perera C (2004) Octreotide treatment for sulfonylurea-induced hypoglycemia. Med J Aust 180(10):540-541

26. Rath S, Naor B-Z, Anderson K, Fahy R, Robeby R (2008) Octreotide in children with hypoglycemia due to sulfonylurea ingestion. J Paediatr Child Health 44:383-384. doi:10.1111/ j.1440-1754.2008.01339.x

27. McLaughlin SA, Crandall CS, McKinney PE (2000) Octreotide: an antidote for sulfonylurea-induced hypoglycemia. Ann Emerg Med 36(2):133-138. doi:10.1067/mem.2000.108183

28. Kutz K, Neusch E, Rosenthalter J (1986) Pharmacokinetics of SMS 201-995 in healthy subjects. Scand J Gastroenterol 21:6572. doi:10.3109/00365528609087433 
29. Chanson P, Timsit J, Harris AG (1993) Clinical pharmacokinetics of octreotide. Therapeutic applications in patients with pituitary tumors. Clin Pharmacokinet 25:375-391

30. Boyle PJ, Justice K, Krentz AJ, Nagy RJ, Schade DS (1993) Octreotide reverses hyperinsulinemia and prevents hypoglycemia induced by sulfonylurea overdose. J Clin Endocrinol Metab 76 (3):752-756. doi:10.1210/jc.76.3.752

31. US Food and Drug Administration, Center for Drug Evaluation and Research (2008) Update on Pediatric Postmarketing Adverse Events. Silver Spring: US Food and Drug Administration. Available from: http://www.fda.gov/ohrms/dockets/ac/08/briefing/ 2008-4399b1-45\%20(Sandostatin\%20(octreotide)\%20Safety\% 20Review\%202008).pdf
32. Nzerue CM, Thomas J, Volcy J, Edeki T (2003) Use of octreotide to treat prolonged sulfonylurea-induced hypoglycemia in a patient with chronic renal failure. Int J Artif Organs 26 (1):86-89

33. Gul M, Cander B, Girisgin S, Ayan M, Kocak S, Unlu A (2006) The effectiveness of various doses of octreotide for sulfonylureainduced hypoglycemia after overdose. Adv Ther 23(6):878-884. doi:10.1007/BF02850209

34. Fasano CJ, O’Malley G, Dominici P, Aguilera E, Latta DR (2008) Comparison of octreotide and standard therapy versus standard therapy alone for the treatment of sulfonylureainduced hypoglycemia. Ann Emerg Med 51(4):400-406. doi:10.1016/j.annemergmed.2007.06.493 